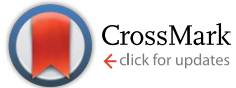

Cite this: Chem. Sci., 2016, 7, 1028

Received 11th September 2015 Accepted 26th October 2015

DOI: $10.1039 / c 5 s c 03437 j$

www.rsc.org/chemicalscience

\title{
Latent harmony in dicarbon between VB and MO theories through orthogonal hybridization of $3 \sigma_{\mathrm{g}}$ and $2 \sigma_{\mathrm{u}}$
}

\begin{abstract}
Ronglin Zhong, $\uparrow$ Min Zhang, $\dagger^{*}$ Hongliang Xu and Zhongmin Su*
Besides the classic double bond scheme, several novel schemes have been proposed to describe the nature of the chemical bond in dicarbon $\left(\mathrm{C}_{2}\right)$, including a quadruple bond and a singlet diradical state. The results from a symmetry-broken CASSCF $(8,8)$ /aug-cc-pVTZ study present a harmony between MO and VB theories, based on the orthogonal hybridization of the $3 \sigma_{\mathrm{g}}$ and $2 \sigma_{\mathrm{u}}$ orbitals together with the other six pristine valence orbitals. This scheme achieves the same bonding energy, $R_{\mathrm{C}-\mathrm{C}}, \omega_{\mathrm{e}}$ and one electron density as that from the eight pristine valence orbitals. A quadruple bond scheme, identical to Prof. Shaik's result from VB theory, is achieved with the $4^{\text {th }}$ bond energy in the range of $12.8-27.6 \mathrm{kcal} \mathrm{mol}^{-1}$. Meanwhile, the weight of a singlet open-shell configuration is the highest among all the possible configurations.
\end{abstract}

\section{Introduction}

Dicarbon $\left(\mathrm{C}_{2}\right)$ is a simple molecule with just two atoms. However, it has aroused many fundamental questions, fascinating mysteries and active discussions in chemistry. ${ }^{1-6}$ It is a colourless gas and is very unstable. A tiny quantity of $\mathrm{C}_{2}$ can be prepared from electric arc strikes, and a good amount of $\mathrm{C}_{2}$ can exist in comets, stellar atmospheres, blue hydrocarbon flames, etc. The $\mathrm{C}-\mathrm{C}$ bond length $\left(R_{\mathrm{C}-\mathrm{C}}\right)$ is $1.243 \AA$ in its ${ }^{1} \Sigma_{\mathrm{g}}^{+}$ground state, and the corresponding vibration frequency $\left(\omega_{\mathrm{e}}\right)$ is 1855 $\mathrm{cm}^{-1},{ }^{2,7}$ At least another 12 excited states have been observed experimentally and the $R_{\mathrm{C}-\mathrm{C}}$ values are found to be in a large range of $1.23 \AA$ to $1.53 \AA \AA^{2,4}$ Among them, two $R_{\mathrm{C}-\mathrm{C}}$ values bear shorter bond lengths in the excited states $\left({ }^{3} \Sigma_{\mathrm{u}}^{+}\right.$and $\left.{ }^{1} \Sigma_{\mathrm{u}}^{+}\right)$than in the ground state. Similar shorter bond lengths in the excited states have also been reported in its cation and anion $\left(\mathrm{C}_{2}{ }^{+}\right.$and $\left.\mathrm{C}_{2}{ }^{-}\right) .^{8-11}$ The $R_{\mathrm{C}-\mathrm{C}}$ of the dicarbide ion $\left(\mathrm{C}_{2}{ }^{2-}\right)$ in crystalline calcium carbide and lithium carbide is shorter than $1.20 \AA \AA^{12,13}$ which is generally accepted as a traditional triple bond $(1 \sigma+2 \pi$ bonds) analogue of $\mathrm{N}_{2}$.

It is worthy of note that the ground $R_{\mathrm{C}-\mathrm{C}}$ distance of $\mathrm{C}_{2}$ is $1.243 \AA$, shorter than the length of any classic $\mathrm{C}=\mathrm{C}$ double bond $\left(1 \sigma+1 \pi\right.$ bonds), such as in ethylene. ${ }^{14}$ Hence, Prof. Shaik ${ }^{15}$ pointed out that suspended $\pi$ bonds may be responsible, since they prefer shorter lengths than $\sigma$ bonds. The essential point of this assumption is that the occupied number of the $2 \sigma_{\mathrm{u}}$ antibond is approximately equal to that of the $2 \sigma_{\mathrm{g}}$

Institute of Functional Material Chemistry \& Local United Engineering Lab for Power Battery, Faculty of Chemistry, Northeast Normal University, Changchun 130024, China.E-mail:mzhang@nenu.edu.cn; zmsu@nenu.edu.cn

$\dagger$ Ronglin Zhong and Min Zhang contributed equally. bond. However, $2 \sigma_{\mathrm{u}}$ is a weak antibonding orbital due to a lower occupied number, which can not counteract the stronger bonding of $2 \sigma_{\mathrm{g}}$. Furthermore, the $\omega_{\mathrm{e}}$ value of $\mathrm{C}_{2}$ is higher than that of ethylene. Hence, soon after, the nature of the $\mathrm{C}_{2}$ bond was said to approach that of a triple bond $(\mathrm{C} \equiv \mathrm{C}) \cdot{ }^{16,17}$ Based on the characteristics of a triple bond in $\mathrm{C}_{2}$, a scheme of a triple bond plus weak coupling by a pair of opposite spinning electrons was proposed in valence bond (VB) theory. ${ }^{18}$ The opposite spinning electron coupling energy was found to be $\sim 12-20.2$ $\mathrm{kcal} \mathrm{mol}^{-1}$ (ref. 19 and 20) at various levels of the theory. In this context, the corresponding $4^{\text {th }}$ bonding scheme of $\mathrm{C}_{2}$ (Fig. 1c) was proposed with VB theory. ${ }^{19}$

A quadruple bond in $\mathrm{C}_{2}$ is certainly reasonable based on quantum mechanics, ${ }^{19,21}$ similar to that in [1.1.1]-propellane. ${ }^{22}$ However, whether it is the best picture to describe the ground state of $\mathrm{C}_{2}$ or not has aroused many active discussions. ${ }^{21,23-26}$ According to traditional molecular orbital (MO) theory, the

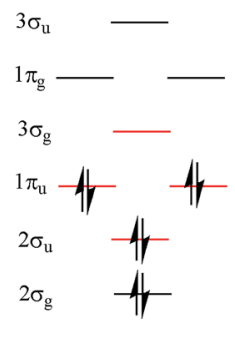

(a) Double Bond

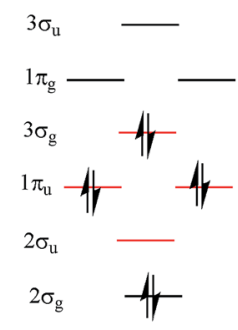

(b) MO's Quadruple Bond

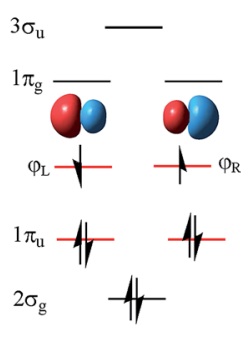

(c) VB's Quadruple Bond
Fig. 1 The configurations of MO's double bond, MO's quadruple bond and VB's quadruple bond schemes in $\mathrm{C}_{2}$. The difference in the order of the occupied orbitals is highlighted with red lines. 
quadruple bond configuration of $\mathrm{C}_{2}$ can be achieved by doubly exciting $2 \sigma_{\mathrm{u}}$ electrons to the $3 \sigma_{\mathrm{g}}$ orbitals. However, a calculation at the CASSCF $(8,8) / c c-p V T Z$ level indicates that the weight of the double bond state (Fig. 1a) is $71.0 \%$ while the weight of the $2 \sigma_{\mathrm{u}}$ $\rightarrow 3 \sigma_{\mathrm{g}}$ quadruple bond counterpart (Fig. 1b) is only $13.6 \% .^{21} \mathrm{On}$ the other hand, the weak $4^{\text {th }}$ bond (the inset in Fig. 1c) was proposed by inequivalent hybridization of the $3 \sigma_{\mathrm{g}}$ and $2 \sigma_{\mathrm{u}}$ occupied states, covering only MO double and quadruple bond configurations, which does not seem perfect. Even in an egalitarian mode, the corresponding bond order of $\mathrm{C}_{2}$ is between two and three. What is the dominant configuration like if orthogonal hybridization of $3 \sigma_{\mathrm{g}}$ and $2 \sigma_{\mathrm{u}}$ is utilized and $100 \%$ weight of multi-configurational self-consistent field (MCSCF) is covered in the calculation? Is there any other configuration that can possess a higher weight in the ground state $\left({ }^{1} \Sigma_{\mathrm{g}}^{+}\right)$of $\mathrm{C}_{2}$ among all the possible configurations?

\section{Results and discussion}

As we know, the ground state of $\mathrm{C}_{2}$ is generally accepted as double $\pi$ bonds in MO theory (shown in Fig. 1a). However, the quasi-degeneracy of the $2 \sigma_{\mathrm{u}}, 3 \sigma_{\mathrm{g}}$ and $1 \pi_{\mathrm{u}}$ orbitals is well known in $\mathrm{C}_{2}$ and its ions, which results in many low-lying excited states of $\mathrm{C}_{2}, \mathrm{C}_{2}{ }^{-}$and $\mathrm{C}_{2}{ }^{+} \cdot{ }^{\mathbf{1}, 2,4}$ The antiferromagnetic diradical characteristic of $\mathrm{C}_{2}$ has also been proposed by the finite-difference pseudopotential method, local spin analysis and VB theory. ${ }^{\mathbf{2 4 - 2 6}}$ Silicon resides in the same column of the periodic table as carbon. The singlet diradical characteristic on a silicon (100) surface is well known. ${ }^{27,28}$ Moreover, dicarbon is a very unstable molecule with a short lifetime, which is easy to dimerize into $\mathrm{C}_{4}$ for instance.

As mentioned above, $\operatorname{CASSCF}(8,8) /$ aug-cc-pVTZ was used in our study because $\mathrm{C}_{2}$ has multi-reference configurations in nature. In the beginning, the level was benchmarked for the ${ }^{1} \Sigma_{\mathrm{g}}^{+}$ground state $\left(\mathrm{KK} 2 \sigma_{\mathrm{g}}^{2} 1 \pi_{\mathrm{xu}}^{2} 1 \pi_{\mathrm{yu}}^{2} 2 \sigma_{\mathrm{u}}^{2}\right)$ and four low-lying $\left({ }^{3} \Pi_{\mathrm{u}}\right.$, ${ }^{3} \Sigma_{\mathrm{u}}^{+},{ }^{3} \Sigma_{\mathrm{g}}^{-}$and ${ }^{1} \Pi_{\mathrm{u}}$ ) excited states. All the potential energy curves are plotted in Fig. 2. Furthermore, the important data of these

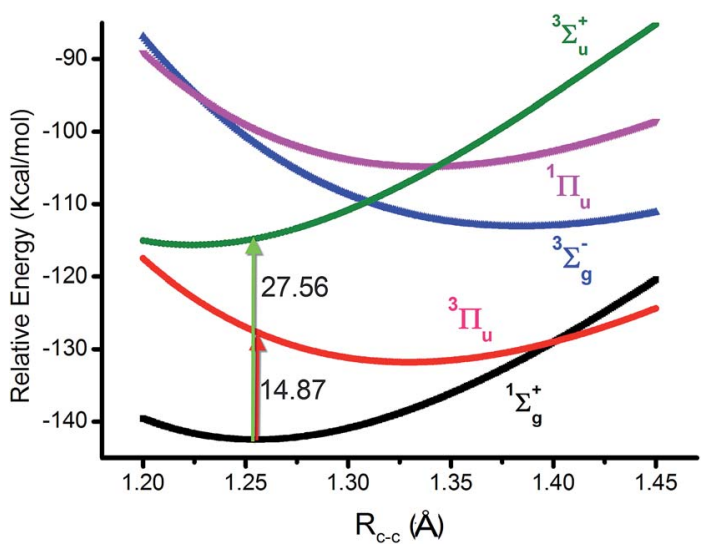

Fig. 2 Plots of $C_{2}$ potential energy curves of ${ }^{1} \Sigma_{g}^{+}$state and four $\left({ }^{3} \Pi_{u}\right.$, ${ }^{3} \Sigma_{\mathrm{u}}^{+},{ }^{3} \Sigma_{\mathrm{g}}^{-}$and ${ }^{1} \Pi_{\mathrm{u}}$ ) excited states at $\operatorname{CASSCF}(8,8) /$ aug-cc-pVTZ level. The bonding energy is relative to two isolated ${ }^{3} \mathrm{P}$ carbon atoms at CASSCF $(4,4)$ /aug-cc-pVTZ level. The vertical transition energies from ${ }^{1} \Sigma_{\mathrm{g}}^{+}$state are also shown. optimized states contrasting to the experimental data are listed in Table 1.

The calculated $R_{\mathrm{C}-\mathrm{C}}$ and $\omega_{\mathrm{e}}$ values of the ${ }^{1} \Sigma_{\mathrm{g}}^{+}$state are close to the experimental values. For example, the bonding energy of the ${ }^{1} \Sigma_{\mathrm{g}}^{+}$state is $-142.5 \mathrm{kcal} \mathrm{mol}^{-1}$, which is almost equivalent to the ideal $R_{\mathrm{C}-\mathrm{C}}$ bonding breakage of $\mathrm{C}_{2}$ based on the heats of formation. ${ }^{23}$ The $R_{\mathrm{C}-\mathrm{C}}$ differences of the other four states compared to the experimental data are only less than $0.02 \AA$. These results clearly show that the results from the $\operatorname{CASSCF}(8,8) /$ aug-cc-pVTZ level are reliable. In the ground state, $3 \sigma_{\mathrm{g}}$ is a weak bond with a one electron density of $\sim 0.4 e$. It contributes somewhat to the stabilization of $\mathrm{C}_{2}$. Hence, a triple bond scheme of $\mathrm{C}_{2}$ is also reasonable. ${ }^{\mathbf{1 6 , 1 7}}$ However, the one electron density of the $2 \sigma_{\mathrm{u}}$ orbital is $\sim 1.6 e$, which is $\sim 1.2 e$ higher than that of the $3 \sigma_{\mathrm{g}}$ orbital. If the populations of all the other three valence orbitals $\left(1 \pi_{\mathrm{xg}}, 1 \pi_{\mathrm{yg}}\right.$ and $\left.3 \sigma_{\mathrm{u}}\right)$ are included, the relative $2 \sigma_{\mathrm{u}}$ antibond electrons are still $\sim 1.0 e$ higher. In this context, the quadruple bond scheme is hard to be accepted by naive application of MO theory.

Based on the traditional valence MOs, it is hard to interpret the singlet diradical characteristic of the $\mathrm{C}_{2}$ ground state, while it has been shown through the finite-difference pseudopotential method and LSA analysis. ${ }^{25,26}$ Even though a singlet diradical state $\left(\mathrm{KK} 2 \sigma_{\mathrm{g}}^{2} 1 \pi_{\mathrm{u}}^{4} 2 \sigma_{\mathrm{u}}^{\downarrow} 3 \sigma_{\mathrm{g}}^{\uparrow}\right)$ was achieved, it is still a ${ }^{1} \Sigma_{\mathrm{u}}^{+}$state. The diagram of $2 \sigma_{\mathrm{u}}^{\downarrow} 3 \sigma_{\mathrm{g}}^{\uparrow}$ occupation is shown in the left part of Fig. 3 . As a result, the MO and VB theories fall into an apparent contradiction. In our opinion, this just indicates that opposite spinning electrons do not locate around the $\mathrm{C}-\mathrm{C}$ bonds, which is in accordance with Prof. Shaik's proposal. However, the difficulty with the VB interpretation of the full configuration interaction (CI) wave function may be due to the nonorthogonal transform and the neglect of $\sim 15 \%$ weight of the configuration state functions (CSFs). Can VB quadruple bond schemes be reliable through the reformed valence MO orbitals? Is it feasible to describe the singlet diradical characteristic of $\mathrm{C}_{2}$ through the reformed valence MO orbitals simultaneously?

We hereby propose another scheme through hybrid orbitals of the $2 \sigma_{\mathrm{u}}$ and $3 \sigma_{\mathrm{g}}$ orbitals to $\varphi_{2 \sigma_{\mathrm{u}}+3 \sigma_{\mathrm{g}}}\left(\varphi_{\mathrm{L}}\right)$ and $\varphi_{2 \sigma_{\mathrm{u}}-3 \sigma_{\mathrm{g}}}\left(\varphi_{\mathrm{R}}\right)$, which was used as the initial active orbital for the CASSCF calculation. It is worthy of note that the $\varphi_{\mathrm{L}}$ and $\varphi_{\mathrm{R}}$ orbitals ensure that the single-occupied electrons are located outside of the $\mathrm{C}-\mathrm{C}$ bond (right part of Fig. 3a). Besides, the other six pristine valence orbitals were maintained. Subsequently, the potential energy curve of the ground state of $\mathrm{C}_{2}$ was re-scanned at the same level with our orbitals. Compared with Prof. Shaik's strategy, the eight CAS orbitals were all orthogonal and the SCFs covered $100 \%$ of the weight. As expected, the new results show that the bonding energy, $R_{\mathrm{C}-\mathrm{C}}, \omega_{\mathrm{e}}$ and one electron density are all the same as the values from the eight pristine valence orbitals (in the first column of Table 1). This is reasonable because the final result is only determined by the one electron densities in the original natural orbitals and the corresponding gradient analysis when all the CSFs are included in the simulations. CASSCF $(8,8)$ and $\operatorname{VBSCF}(1764)$ span the same space of 1764 configurations in MO and VB theories, separately. Theoretically, the same electron correlation energy and bonding energy can be achieved if the same orbitals are adopted in the 
Table 1 The most important theoretical data of the five states, including $R_{\mathrm{C}-\mathrm{CS}}(\AA)$ and vibrational frequencies $\left(\omega_{\mathrm{e}}, \mathrm{cm}^{-1}\right)$, together with their experimental data (shown in bracket)

\begin{tabular}{|c|c|c|c|c|c|}
\hline & ${ }^{1} \Sigma_{\mathrm{g}}^{+}$ & ${ }^{3} \Pi_{\mathrm{u}}$ & ${ }^{3} \Sigma_{\mathrm{u}}^{+}$ & ${ }^{3} \Sigma_{\mathrm{g}}^{-}$ & ${ }^{1} \Pi_{\mathrm{u}}$ \\
\hline $\boldsymbol{R}_{\mathrm{C}-\mathrm{C}}(\AA)$ & $1.255(1.243)$ & $1.330(1.312)$ & $1.224(1.230)$ & $1.384(1.369)$ & $1.338(1.318)$ \\
\hline$\Delta E_{\text {relat. }}\left(\mathrm{kcal} \mathrm{mol}^{-1}\right)$ & $-142.5(-142)$ & -131.8 & -114.9 & -113.1 & -104.7 \\
\hline Dominant configuration & $\begin{array}{l}\mathrm{KK} 2 \sigma_{\mathrm{g}}^{2} \\
1 \pi_{\mathrm{xu}}^{2} 1 \pi_{\mathrm{yu}}^{2} 2 \sigma_{\mathrm{u}}^{2}\end{array}$ & $\begin{array}{l}\mathrm{KK} 2 \sigma_{\mathrm{g}}^{2} 2 \sigma_{\mathrm{u}}^{2} \\
1 \pi_{\mathrm{xu}}^{2} 1 \pi_{\mathrm{yu}}^{\alpha} 3 \sigma_{\mathrm{g}}^{\alpha}\end{array}$ & $\begin{array}{l}\mathrm{KK} 2 \sigma_{\mathrm{g}}^{2} 1 \pi_{\mathrm{xu}}^{2} \\
1 \pi_{\mathrm{yu}}^{2} 2 \sigma_{\mathrm{u}}^{\alpha} 3 \sigma_{\mathrm{g}}^{\beta}\end{array}$ & $\begin{array}{l}\mathrm{KK} 2 \sigma_{\mathrm{g}}^{2} 2 \sigma_{\mathrm{u}}^{2} \\
3 \sigma_{\mathrm{g}}^{2} 1 \pi_{\mathrm{xu}}^{\alpha} 1 \pi_{\mathrm{yu}}^{\alpha}\end{array}$ & $\begin{array}{l}\mathrm{KK} 2 \sigma_{\mathrm{g}}^{2} 2 \sigma_{\mathrm{u}}^{2} \\
1 \pi_{\mathrm{xu}}^{2} 1 \pi_{\mathrm{yu}}^{\alpha} 3 \sigma_{\mathrm{g}}^{\beta}\end{array}$ \\
\hline ЕВО & 2.15 & 1.90 & 2.74 & 1.92 & 1.90 \\
\hline & $0.115 e\left(1 \pi_{\mathrm{yg}}\right)$ & $0.074 e\left(1 \pi_{\mathrm{yg}}\right)$ & $0.109 e\left(1 \pi_{\mathrm{yg}}\right)$ & $0.048 e\left(1 \pi_{\mathrm{yg}}\right)$ & $0.041 e\left(1 \pi_{\mathrm{yg}}\right)$ \\
\hline & $0.115 e\left(1 \pi_{\mathrm{xg}}\right)$ & $0.098 e\left(1 \pi_{\mathrm{xg}}\right)$ & $0.109 e\left(1 \pi_{\mathrm{xg}}\right)$ & $0.048 e\left(1 \pi_{\mathrm{xg}}\right)$ & $0.097 e\left(1 \pi_{\mathrm{xg}}\right)$ \\
\hline & $0.393 e\left(3 \sigma_{\mathrm{g}}\right)$ & $0.965 e\left(1 \pi_{\mathrm{yu}}\right)$ & $0.976 e\left(3 \sigma_{\mathrm{g}}\right)$ & $0.990 e\left(1 \pi_{\mathrm{xu}}\right)$ & $0.985 e\left(1 \pi_{\mathrm{yu}}\right)$ \\
\hline & $1.602 e\left(2 \sigma_{\mathrm{u}}\right)$ & $1.045 e\left(3 \sigma_{\mathrm{g}}\right)$ & $1.031 e\left(2 \sigma_{\mathrm{u}}\right)$ & $0.990 e\left(1 \pi_{\mathrm{yu}}\right)$ & $1.023 e\left(3 \sigma_{\mathrm{g}}\right)$ \\
\hline & $1.888 e\left(1 \pi_{\mathrm{yu}}\right)$ & $1.905 e\left(1 \pi_{\mathrm{xu}}\right)$ & $1.891 e\left(1 \pi_{\mathrm{yu}}\right)$ & $1.956 e\left(2 \sigma_{\mathrm{u}}\right)$ & $1.912 e\left(1 \pi_{\mathrm{xu}}\right)$ \\
\hline & $1.888 e\left(1 \pi_{\mathrm{xu}}\right)$ & $1.910 e\left(2 \sigma_{\mathrm{u}}\right)$ & $1.891 e\left(1 \pi_{\mathrm{xu}}\right)$ & $1.966 e\left(3 \sigma_{\mathrm{g}}\right)$ & $1.933 e\left(2 \sigma_{\mathrm{u}}\right)$ \\
\hline
\end{tabular}

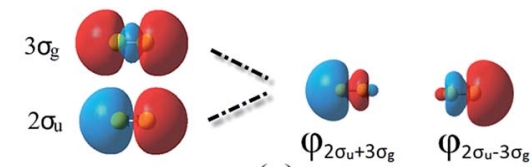

(a)

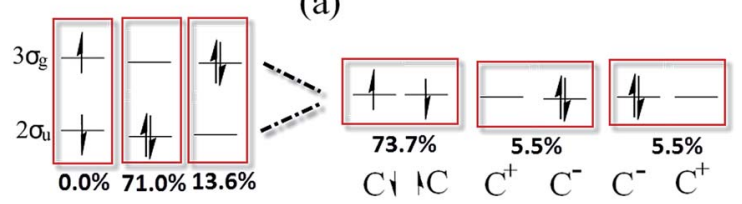

(b)

Fig. 3 Equivalent hybridized orbitals of $\varphi_{\mathrm{L}}$ and $\varphi_{\mathrm{R}}$ from $2 \sigma_{\mathrm{u}}$ and $3 \sigma_{\mathrm{g}}$ localized around a single $C$ atom (a) and the corresponding potential occupied styles before and after hybridization (b)

simulation. Unfortunately, orthogonal orbitals are adopted in the former, but the nonorthogonal orbitals are adopted in the latter. ${ }^{18}$

The difference between our and Prof. Frenking's CASSCF schemes ${ }^{21}$ is the input active orbitals and their corresponding CSF weights, which are affected by the input orbital styles. The five highest weight configurations of our scheme are shown in

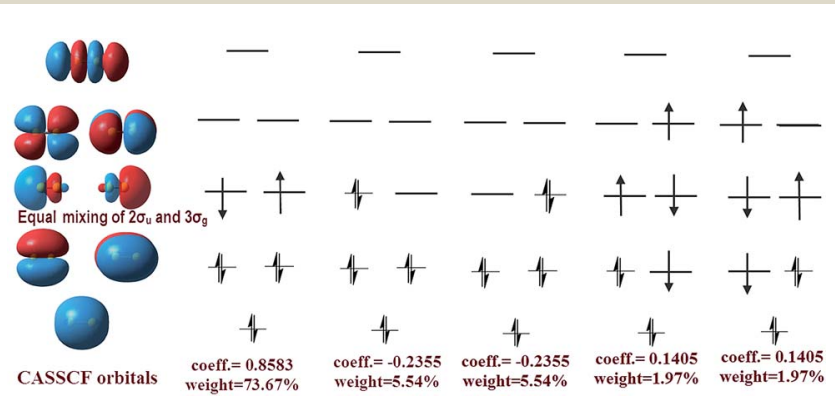

Fig. 4 Left: CASSCF orbitals, including $\varphi_{\mathrm{L}}$ and $\varphi_{\mathrm{R}}$. Right: The corresponding five most important configurations of a full-valence CASSCF $(8,8)$ /aug-CC-PVTZ calculation of $C_{2}$, showing the coefficients and the weights of the configurations.
Fig. 4. The weight of the highest configuration $\left(\mathrm{KK} 2 \sigma_{\mathrm{g}}^{2} 1 \pi_{\mathrm{xu}}^{2} 1 \pi_{\mathrm{yu}}^{2} \varphi_{\mathrm{L}}^{\downarrow} \varphi_{\mathrm{R}}^{\uparrow}\right)$ is $73.7 \%$, around $2.7 \%$ higher than that of Prof. Frenking's (KK2 $\left.\sigma_{\mathrm{g}}^{2} 1 \pi_{\mathrm{xu}}^{2} 1 \pi_{\mathrm{yu}}^{2} 2 \sigma_{\mathrm{u}}^{2}\right)$. The results elucidate that the spin-localization of the $2 \sigma_{\mathrm{u}}$ electrons is, indeed, outside of the $\mathrm{C}-\mathrm{C}$ bond, in accordance with the VB view. ${ }^{18,19}$ If the bonding nature is estimated by the highest weight configuration, the ground state of $\mathrm{C}_{2}$ is inclined to be a singlet diradical due to a little higher weight than the traditional double bond configuration.

However, with our understanding from VB theory, the first three configurations have to be added up, since there is a combination of a major covalent structure $\left(\mathrm{C}^{\downarrow}-\mathrm{C}^{\uparrow}\right)$, and two minor ionic ones $\left(\mathrm{C}^{-}-\mathrm{C}^{+}\right.$and $\left.\mathrm{C}^{+}-\mathrm{C}^{-}\right)$. They all belong to the $4^{\text {th }}$ bond. To our surprise, the total weight of the three highest configurations is equal to the weight sum of the classic MO double and quadruple bond configurations (Fig. 3b), namely the initial value in Prof. Shaik's nonorthogonal scheme. Hence, the corresponding covalent component of the $4^{\text {th }}$ bond is $84.8 \%$ (close to the weight of the ${ }^{3} \Pi_{\mathrm{u}}$ and ${ }^{3} \Sigma_{\mathrm{u}}^{-}$states). The opposite spin coupling energy between $\varphi_{\mathrm{L}}^{\downarrow} \varphi_{\mathrm{R}}^{\uparrow}$ can not be achieved directly in our orthogonal schemes. If the vertical excited energy from the ${ }^{1} \Sigma_{\mathrm{g}}^{+}$to ${ }^{3} \Pi_{\mathrm{u}}$ states $\left(R_{\mathrm{C}-\mathrm{C}}\right.$ is $\left.1.253 \AA\right)$ is the minimum to break the coupling energy of $\varphi_{\mathrm{L}}$ and $\varphi_{\mathrm{R}}$, the relevant value is 12.8-15.1 $\mathrm{kcal} \mathrm{mol}^{-1}$ (depending on the calculated weight), which is also consistent with the VB results. If the correct decoupled triplet state ${ }^{3} \Sigma_{\mathrm{u}}^{+}$is utilized as the electron spin-flip energy, the maximum of the $4^{\text {th }}$ bonding energy is $27.56 \mathrm{kcal} \mathrm{mol}^{-1}$. Hence, the $\mathrm{VB} 4^{\text {th }}$ bond based on Lewis electron pairing is reasonable. The results of our scheme implement an inherent harmony between VB and MO theories.

Furthermore, we focus on the Effective Bond Order (ЕBO) based on the one electron density of the ground state in Table $1 .^{29}$ The EBO of $2 \sigma_{\mathrm{g}}-2 \sigma_{\mathrm{u}}$ is 0.191 and that of $3 \sigma_{\mathrm{g}}-3 \sigma_{\mathrm{u}}$ is 0.190 . How to define their bond orders is still a problem. No $\sigma$ bond or two weak $\sigma$ bonds? If no $\sigma$ bond, then it is a classic double bond scheme. If two weak $\sigma$ bonds, then it is another quadruple bond scheme. Anyway, the EBO results at least demonstrate that the two $\pi$ bonds contribute most to the bonding energy if the ${ }^{3} \mathrm{P}$ 
state of the carbon atom is a starting point. That is the reason why the $\mathrm{C}-\mathrm{C}$ bonding breakage of $\mathrm{C}_{2}$ is smaller than that of ethylene $\left(-172 \mathrm{kcal} \mathrm{mol}^{-1}\right)$. In our simulation, the highest EBO is 2.74 for the ${ }^{3} \Sigma_{\mathrm{u}}^{+}$state, because of the occupied number of $0.976 e$ in the $3 \sigma_{\mathrm{g}}$ orbitals. Some distribution of $3 \sigma_{\mathrm{g}}$ locates between the two carbon atoms. A similar contribution is from the lower occupied number of $1.031 e$ in the $2 \sigma_{\mathrm{u}}$ orbitals. Hence, its $R_{\mathrm{C}-\mathrm{C}}$ value is $\sim 0.03 \AA$ shorter than the $R_{\mathrm{C}-\mathrm{C}}$ value of the ground state, and the corresponding $\omega_{\mathrm{e}}$ value is the highest.

In the end, we would like to say a little more about the nature of the chemical bond in $\mathrm{C}_{2}$ with an ancient Chinese poem about Mountain Lu written by Su Shi: "It's a range viewed in face and peaks from the side. Assuming different shapes viewed from far and wide. Of the Mountain Lu we cannot make out the true face. For we are lost in the heart of the very place". ${ }^{30}$ We are shown that the shape and scenery of Mountain Lu are different from different perspectives. Similarly, the understanding of "the most rigorous theory" ${ }^{23}$ for $\mathrm{C}_{2}$ perhaps depends on the various viewpoints of chemists.

\section{Conclusions}

In summary, a quadruple bond scheme identical to Prof. Shaik's result from VB theory is achieved, which is related to its $R_{\mathrm{C}-\mathrm{C}}$ length. Meanwhile, the weak $4^{\text {th }}$ bond or the singlet diradical characteristic of $\mathrm{C}_{2}$ is also easy to be understood, and is related to its instable/reactive nature. Our study conquers the shortcoming of traditional valence MOs. It is worthy of note that $\mathrm{C}_{2}$ must have multi-reference configurations in nature due to having no energy difference among these schemes. The only difference is the dominant contribution in the total CSFs, and how to understand them.

\section{Methodology}

Based on the calculations in previous references, ${ }^{21,23}$ the precision achieved by $\operatorname{CASSCF}(8,8)$, which covers the CSFs excited including all the valence electron orbitals, is as good as full CI, since it is commonly recognized that the weights of the inner $1 \sigma_{\mathrm{g}}^{2} 1 \sigma_{\mathrm{u}}^{2}$ orbitals are always $100 \%$ in full CI simulations. The configurations of the $\mathrm{C}_{2}$ electronic states are constructed directly from combinations of natural atomic orbitals in our simulations, because natural orbitals, as a particularly efficient choice, possess the unique advantage of minimizing the mixing effect of the $2 s-2 p$ orbitals in carbon and eliminating the diversification of LCAO-MOs in MCSCF simulations. ${ }^{31-34}$ All the calculations were performed mainly based on the GAUSSIAN 09 program package. ${ }^{35}$

\section{Acknowledgements}

This work was financially supported by the National Nature Science Foundation of China (No. 21203020 and 21131001), National Nature Science Foundation of Jilin Prov. (No. 20150101006JC) and Thirteen Five-Year Sci-tech Research Guideline of the Education Department of Jilin Prov, China.

\section{Notes and references}

1 R. S. Mulliken, Phys. Rev., 1939, 56, 778-781.

2 R. Hoffmann, Am. Sci., 1995, 83, 309-311.

3 W. Weltner and R. J. van Zee, Chem. Rev., 1989, 89, 17131747.

4 M. Martin, J. Photochem. Photobiol., A, 1992, 66, 263-289.

5 P. S. Skell and J. H. Plonka, J. Am. Chem. Soc., 1970, 92, 56205624.

6 P. S. Skell, K. J. Klabunde and F. A. Fagone, J. Am. Chem. Soc., 1972, 94, 7862-7866.

7 M. Douay, R. Nietmann and P. F. Bernath, J. Mol. Spectrosc., 1988, 131, 250-260.

8 R. D. Mead, U. Hefter, P. A. Schulz and W. C. Lineberger, J. Chem. Phys., 1985, 82, 1723-1731.

9 D. Forney, H. Althaus and J. P. Maier, J. Phys. Chem., 1987, 91, 6458-6461.

10 M. Rösslein, M. Wyttenbach and J. P. Maier, J. Chem. Phys., 1987, 87, 6770-6772.

11 J. P. Maier and M. Rösslein, J. Chem. Phys., 1988, 88, 46144620.

12 M. Atoji, J. Chem. Phys., 1961, 35, 1950-1960.

13 R. Juza, V. Wehle and H.-U. Schuster, Z. Anorg. Allg. Chem., 1967, 352, 252-257.

14 E. D. Jemmis, B. Pathak, R. B. King and H. F. Schaefer Iii, Chem. Commun., 2006, 2164-2166.

15 J. M. Galbraith, E. Blank, S. Shaik and P. C. Hiberty, Chem.Eur. J., 2000, 6, 2425-2434.

16 P. Pyykkö, S. Riedel and M. Patzschke, Chem.-Eur. J., 2005, 11, 3511-3520.

17 D. R. Huntley, G. Markopoulos, P. M. Donovan, L. T. Scott and R. Hoffmann, Angew. Chem., Int. Ed., 2005, 44, 75497553.

18 P. Su, J. Wu, J. Gu, W. Wu, S. Shaik and P. C. Hiberty, J. Chem. Theory Comput., 2011, 7, 121-130.

19 S. Shaik, D. Danovich, W. Wu, P. Su, H. S. Rzepa and P. C. Hiberty, Nat. Chem., 2012, 4, 195-200.

20 D. Danovich, P. C. Hiberty, W. Wu, H. S. Rzepa and S. Shaik, Chem.-Eur. J., 2014, 20, 6220-6232.

21 G. Frenking and M. Hermann, Angew. Chem., Int. Ed., 2013, 52, 5922-5925.

22 W. Wu, J. Gu, J. Song, S. Shaik and P. C. Hiberty, Angew. Chem., Int. Ed., 2009, 48, 1407-1410.

23 S. Shaik, H. S. Rzepa and R. Hoffmann, Angew. Chem., Int. Ed., 2013, 52, 3020-3033.

24 L. T. Xu and T. H. Dunning, J. Chem. Theory Comput., 2014, 10, 195-201.

25 J. R. Chelikowsky, N. Troullier, K. Wu and Y. Saad, Phys. Rev. B: Condens. Matter Mater. Phys., 1994, 50, 11355-11364.

26 E. Ramos-Cordoba, P. Salvador and M. Reiher, Chem.-Eur. J., 2013, 19, 15267-15275.

27 C. H. Choi, D.-J. Liu, J. W. Evans and M. S. Gordon, J. Am. Chem. Soc., 2002, 124, 8730-8740.

28 X. Lu, M. Zhu, X. Wang and Q. Zhang, J. Phys. Chem. B, 2004, 108, 4478-4484. 
29 B. O. Roos, A. C. Borin and L. Gagliardi, Angew. Chem., Int. Ed., 2007, 46, 1469-1472.

$30 \mathrm{~S}$. Su, Written on the wall at West Forest Temple. This version is translated by $\mathrm{Xu}$ Yuanchong.

31 P. O. Löwdin, Phys. Rev., 1955, 97, 1474-1489.

32 P. O. Löwdin, Phys. Rev., 1955, 97, 1490-1508.

33 P. O. Löwdin, Phys. Rev., 1955, 97, 1509-1520.

34 E. R. Davidson, Rev. Mod. Phys., 1972, 44, 451-464.

35 M. J. Frisch, G. W. Trucks, H. B. Schlegel, G. E. Scuseria, M. A. Robb, J. R. Cheeseman, J. A. Montgomery, J. Vreven, T. K. N. Kudin, J. C. Burant, J. M. Millam, S. S. Iyengar, J. Tomasi, V. Barone, B. Mennucci, M. Cossi, G. Scalmani, N. Rega, G. A. Petersson, H. Nakatsuji, M. Hada, M. Ehara, K. Toyota, R. Fukuda, J. Hasegawa, M. Ishida, T. Nakajima, Y. Honda, O. Kitao, H. Nakai, M. Klene, X. Li, J. E. Knox,
H. P. Hratchian, J. B. Cross, V. Bakken, C. Adamo, J. Jaramillo, R. Gomperts, R. E. Stratmann, O. Yazyev, A. J. Austin, R. Cammi, C. Pomelli, J. W. Ochterski, P. Y. Ayala, K. Morokuma, G. A. Voth, P. Salvador, J. J. Dannenberg, V. G. Zakrzewski, S. Dapprich, A. D. Daniels, M. C. Strain, O. Farkas, D. K. Malick, A. D. Rabuck, K. Raghavachari, J. B. Foresman, J. V. Ortiz, Q. Cui, A. G. Baboul, S. Clifford, J. Cioslowski, B. B. Stefanov, G. Liu, A. Liashenko, P. Piskorz, I. Komaromi, R. L. Martin, D. J. Fox, T. Keith, M. A. AlLaham, C. Y. Peng, A. Nanayakkara, M. Challacombe, P. M. W. Gill, B. Johnson, W. Chen, M. W. Wong, C. Gonzalez and J. A. Pople, Gaussian 09w, Revision A.02, Gaussian, Inc., Wallingford, CT, 2009. 